\title{
As funções léxicas na descrição de colocações integradas por verbos de cambio do espanhol
}

\author{
Mila González da Cunha
}

\section{RESUMO}

O presente trabalho parte de colocações integradas pelos verbos de cambio hacerse, ponerse e volverse, identificadas em um corpus do espanhol através de programa de computador. Os dados obtidos são, então, descritos por meio das funções léxicas.As funções léxicas constituem uma linguagem formal criada no âmbito da Teoria Sentido-Texto para descrever de maneira sistemática todos os tipos de relações léxicas entre as unidades léxicas de qualquer língua (MEL'ČUK, 1996: 38). Com as funções léxicas se espera fornecer para qualquer unidade léxica todas as demais unidades léxicas a ela relacionadas de modo a suprir as necessidades do falante nas suas escolhas lexicamente direcionadas, dentre elas as colocações.Esse processo é inspirado na proposta de Thierry Fontanelle (1998), que parte de colocações identificadas através de critérios de frequência, para, então, descrevê-las utilizando-se do aparato teórico das funções léxicas.

Os chamados verbos de cambio do espanhol fazem parte dos verbos semicopulativos. Os verbos semicopulativos se diferenciam dos copulativos em dois pontos. Em primeiro lugar, acrescentam à construção um conteúdo, normalmente modal ou aspectual, além de ligar um argumento a um atributo. Ao contrário dos copulativos, esses verbos possuem uma forma plena que seleciona argumentos. Temos um verbo semicopulativo, por exemplo, em Luis se puso morado e um verbo pleno em Luis se puso el sombrero en la cabeza (REAL ACADEMIA ESPAÑola; AsOCIACIÓN DE ACADEMIAS AMERICANAS, 2009, p.2835-2836).

Os verbos de cambio referem o processo de "passar a um estado, alcançá-lo ou desembocar nele". Ao contrário de outras línguas, o espanhol não possui um verbo para expressar o significado de mudança de estado, mas um paradigma de distribuição mais complexa com os verbos devenir, hacerse, llegar a ser, pasar a ser, ponerse, quedarse tornarse ou volverse (ReAl ACADEMIA EsPAÑola; Asociación DE ACADEMIAS AMERICANAS, 2009, p. 2837).

Esses verbos, contudo, não podem ser substituídos uns pelos outros livremente. Nas gramáticas de uma maneira geral é comum que as diferenças de significado sejam 
entreCaminos, v.1, jul-dez 2015

apresentadas como justificativa para a escolha de um desses verbos em determinadas construções. Nesse sentido, Demonte e Masullo (2000) ressalvam que embora o complemento denote uma mudança de estado, essa mudança não adquire o mesmo status com todos os verbos. Por exemplo, ponerse indica uma mudança transitória enquanto volverse e tornarse indicam uma mudança indefinida ou mais ou menos permanente: $\mathrm{Mi}$ padre se puso loco (= furioso). (Cf. Mi padre se volvió loco (= demente) (DEMONTE; MASULLO, 2000, p. 2512).

No entanto, a descrição dos usos dos verbos de cambio, em termos de nuances de significado aportadas à construção que integram, nem sempre é suficiente. É possível notar padrões de ocorrência que não se justificam pelo significado desses verbos, sobretudo na análise de dados obtidos em corpora. Por exemplo, a pesquisa com a construção volverse loco(a) no Corpus del Español (DAVIES, 2002) aponta ocorrências como:

1) cosas que hacer no te los mandan y a mí me... me vuelven loca, porque me he escrito así como ya sesenta o setenta cartas reclamándolos, ${ }^{1}$

2) Jacques Copeau, el famoso actor y director del Teatro del Vieux Colombier, quien volvió loco a todo París con nuestra Perricholi representando con un gusto exquisito la comedia de

O problema com a ênfase nas diferenças semânticas dos verbos de cambio reside no fato de que se trata de verbos de pouco conteúdo semântico, praticamente esvaziados de significado. Para Demonte e Masullo (2000) as construções com verbos de cambio constituem um subgrupo dos complementos predicativos selecionados lexicamente (sua ausência afasta a gramaticalidade) por verbos intransitivos semanticamente enfraquecidos. Outro subgrupo é o de construções com esse tipo de complemento predicativo unido a verbos semanticamente fracos e verbos suporte.

Nesse sentido a gramática da Real Academia Española e Asociación de Academias Americanas (2009), ao tratar dos verbos semicopulativos, faz referência ao tipo de mudança que cada verbo expressa, ou seja, ao significado do verbo, mas também a (...) algunas

\footnotetext{
$1 \quad$ A interface do site que contém o corpus consultado apresenta as ocorrências para a pesquisa realizada no formato PCEC (palavra clave en contexto - palavra chave em contexto), de modo que apenas uma pequena quantidade de texto de ambos os lados da expressão pesquisada é exibida.
} 
entreCaminos, v.1, jul-dez 2015

tendencias que justifican la preferencia por varios de estos verbos en función del atributo (...)(p. 2837). A respeito do verbo hacerse, por exemplo, se afirma que são mais frequentes os substantivos que referem mudanças de natureza profissional ou social, como se hizo amigo, me hice novio, me hago cómplice, me hice marxista leninista, me hice bailarín (REAL ACAdemia Española; Asociación de ACAdemias Americanas, 2009, p. 2840).

Diante das dificuldades na descrição dos usos dos verbos de cambio, sobretudo com vistas ao ensino desses verbos a aprendizes de espanhol como língua estrangeira, se faz necessária uma abordagem que abarque essas peculiaridades. Uma forma de encontrar e descrever regularidades no uso desses verbos é analisar as construções por eles integradas que são colocações.

Não há consenso acerca da noção de colocação. No âmbito do contextualismo britânico, Sinclair (1991) afirma que a colocação é uma das formas de co-ocorrência de palavras que parecem ser escolhidas em pares ou em grupos, não necessariamente adjacentes. A análise dos padrões de co-ocorrência de palavras em um corpus permite perceber construções que ocorrem com mais frequência do que seria esperado pelo simples acaso. Isso ocorre porque essas construções são resultado de uma única escolha que recai simultaneamente sobre mais de uma palavra.

Outros autores, a partir de diferentes teorias, tratam do fenômeno das colocações. Embora os limites entre uma construção livre e uma colocação variem, de uma maneira geral está presente a noção de que a colocação não é construída exclusivamente com base no sentido das palavras e na gramática da língua, havendo uma forte ligação entre os itens que a integram.

Uma das maneiras de identificar colocações é mensurar a co-ocorrência de palavras em um ou mais corpora. O critério estatístico, contudo, não é capaz de fornecer informação semântica sobre as colocações assim identificadas. A pesquisa em corpora permite atestar que determinadas construções ocorrem com regularidade, mas não há como sistematizar esse conhecimento, o que dificulta bastante o ensino das colocações. 


\section{As funções léxicas}

Introduzidas por Zolkovsky e Mel'čuk (1967 apud MEL'ČUK, 1998), as funções léxicas constituem uma linguagem formal desenvolvida no âmbito da teoria Sentido-Texto (TST) para descrever as relações derivativas e colocacionais entre unidades léxicas. As relações derivativas correspondem às funções léxicas paradigmáticas, enquanto as colocacionais correspondem às funções léxicas sintagmáticas. Segundo Mel'čuk (2001, p.5-6) Paradigmatic LFs correspond to derivational relations well known in linguistics: synonymy, antonymy, conversion, nominalization, agent/patient noun, relative adjective, etc. ${ }^{2}$

Para a teoria Sentido-Texto as colocações são casos de co-ocorrência léxica restrita, ou seja, uma colocação $A B$ se caracteriza pelo fato de que seu significado é construído a partir do significado de um dos lexemas constituintes, A, por exemplo, e do significado que o outro lexema $B$ exibe em contingência com $A$, de modo que a escolha de $B$ é restrita em função do lexema A (MEL'ČUK, 1998). O sentido 'intenso', por exemplo, se manifesta lexicamente por meio do lexema ímprobo em esfuerzo ímprobo, mas como febril em una atividad febril ou ainda encarnizado em una lucha encarnizada (ALONSO RAMOS, 1993, p. 149).

A função léxica $(F L)$ é inspirada na noção de função em sentido matemático $f(x)=y$. Ao invés de relacionar valores numéricos, a função léxica relaciona itens lexicais.Uma FL representa a relação entre uma palavra $L$, que é o argumento da função f, e os seus valores, um conjunto de palavras que é representado por $\mathrm{f}(\mathrm{L})$. Para evitar abiguidade é usada a denominação palavra-chave no lugar do termo matemático argumento, já que este também existe na linguística.

Em uma FL a relação entre palavra-chave e valor é tal que se tomamos duas palavras $W^{1}$ e $W^{2}$ e aplicamos a elas a mesma função léxica $f$ (se esta existe para ambos os argumentos), temos que $f\left(L^{1}\right)$ e $f\left(L^{2}\right)$ constituem a mesma relação sintática e semântica. $\mathrm{Na}$ maior parte das vezes os valores de $f\left(W^{1}\right)$ e $f\left(W^{2}\right)$ serão diferentes, o que significa que a função e seu valor estão ligados fraseologicamente (MEL'ČUK, 1981, p. 39).

2 Tradução livre: FLs paradigmáticas correspondem a relações derivacionais bem conhecidas em
linguística: sinonímia, antinonímia, conversão, nominalização, nome agente/patiente, adjetivo relativo, etc. 
As FLs são representadas por uma abreviatura de quatro letras de uma palavra latina. Até o momento cerca de $60 \mathrm{FLs}$ foram reconhecidas nas línguas naturais. A função léxica Magn, por exemplo, fornece os valores que intensificam a palavra-chave quando co-ocorrem com esta (MeL'ČUk, 2001, p. 6):

$$
\begin{aligned}
& \text { Magn(loco crazy) = como una cabra as a she-goat } \\
& \text { Magn(tr fico traffic) = denso dense } \\
& \text { Magn(silencio silence) = profundo profound }
\end{aligned}
$$

Com as FLs se espera poder descrever todas as colocações das línguas naturais. Para que essa descrição seja feita, muitas vezes é necessário combiná-las para formar FLs complexas. O valor de uma FL complexa corresponde a uma expressão que abrange o sentido da combinação como um todo, p. ex., IncepPred(enfermo) $=$ caer, $_{\text {ponerse }}^{3}$ (ALONSO RAMOS, 1993, MEL'ČUK, 1996).

\section{Aplicação das FLs}

A título de exemplo da aplicação das funções léxicas, analisamos a colocação hacer(se) realidad, identificada a partir de busca realizada no Corpus del Español (DAVIES, 2002). A pesquisa foi feita na seção do referido corpus relativa ao século $X X$, que contém amostras de registro oral (5.113.249), textos de ficção (5.144.073), acadêmicos (5.138.077) e jornalísticos (5.144.631), totalizando 20.540 .030 palavras. O termo realidad é o 14 o substantivo mais frequente no espaço de quatro palavras à direita de uma construção formada por um pronome pessoal e o lema hacer. Das 52 ocorrências encontradas, apenas nove não apresentavam realidad como complemento de hacer (por exemplo, me hacía pensar que en realidad).

Das 43 ocorrências restantes, pudemos verificar que quatro delas são de usos de hacer com sentido causativo e as demais de verbo de cambio. São exemplos, respectivamente:

\footnotetext{
3 A FL Pred pode tomar adjetivos como palavra-chave, permitindo que o adjetivo apareça na oração sem acrescentar qualquer significado, como ocorre com os verbos suporte, p. ex. Pred (enfermo) $=$ estar (ALONSO RAMOS, 1993). A FL Incep é tratada mais adiante.
} 
3) Y lo que puede ser factible hoy en roedores, quizá la ciencia lo haga realidad mañana en el hombre.

4) Después de tanto tiempo, mi sueño se hizo realidad. Conseguí el trabajo en el interior que tanto anhelaba.

Não há uma função léxica que expresse a noção de mudança da mesma forma que Magn expressa a noção de intensidade, por exemplo. As FLs que melhor se adaptam à descrição dos verbos de cambio são as chamadas FLs fasais, Incep, Cont e Fin, que correspondem respectivamente ao início, continuação e final de um processo. Alonso Ramos (1993) ressalta que para a TST as noções de duração, incoação e terminação de um processo não são consideradas aspectuais e sim temporais. Essas FLs integram necessariamente FLs complexas, p. ex. (Alonso Ramos, 1993, p. 466).:

$$
\begin{aligned}
& \text { IncepOper } 1 \text { (huelga })=\text { ponerse de, } \\
& \text { IncepPred }(\text { enfermo })=\text { caer, } \text { ponerse, } \\
& \text { IncepPred }(\text { loco })=\text { volverse } \\
& \text { IncepPred }(\text { pálido })=\text { ponerse } / / \text { empalidecer }
\end{aligned}
$$

Embora o verbo hacer possa funcionar como verbo de apoio, a análise das ocorrências encontradas mostra que combinado com o substantivo realidad esse verbo aporta à expressão a noção de mudança. No exemplo acima temos Incep associada a Oper $_{1}$, que é a FL usada para descrever um verbo de apoio que toma a palavra-chave como complemento. Alonso Ramos (2004) registra o fato de que muitas vezes um verbo fasal é oferecido como substituto de um verbo de apoio, dada a proximidade semântica e sintática entre ambos. Contudo esses verbos se diferenciam semanticamente pois o verbo de apoio é vazio de significado. Além disso, a autora ressalta que nomes que tomam o mesmo verbo de apoio podem selecionar verbos fasais diferentes, nem sempre havendo uma contrapartida com verbo de apoio para uma construção com verbo fasal, como por exemplo entrar ganas.

As FLs que produzem como valor um verbo causativo descrevem uma modificação na estrutura sintática da construção descrita, acrescentando um novo participante à situação, o 
causador (MEL'ČUK, 1996). Para que a estrutura sintática da construção possa ser explicitada, Caus se combina com uma FL de verbo semanticamente vazio, ou seja, de verbo de apoio. Essa estrutura é capaz de retratar uma colocação com verbo causativo que é uma contrapartida de um verbo de cambio, pois a FL Caus traz em si a noção de começo. Conforme Alonso Ramos (1993), Caus não se combina com nenhuma FL fasal, pois de um ponto de vista semântico a "causação" é sempre de um começo, de uma continuação ou uma cessação. Por isso no $\mathrm{DEC}^{4}$ se optou por marcar CausIncep apenas como Caus.

Na pesquisa acima mencionada, a baixa ocorrência de hacer como causativo pode ser consequência do parâmetro de busca utilizado, pois nesse uso o verbo não é pronominal. Para verificar essa hipótese procedemos à busca, no mesmo corpus, das ocorrências de verbos (sem a especificação da co-ocorrência com pronomes) nas quatro posições à esquerda de realidad. Obtivemos 2.903 ocorrências, das quais 153 são com hacer, o segundo verbo mais frequente (o primeiro é ser com 607 ocorrências).

A busca dos verbos que ocorrem nas quatro posições à esquerda de realidad revelou 30 ocorrências com volver(se) e 11 com poner(se) $)^{5}$. Com volver a construção predominante é volver a la realidad, sendo que nas demais ocorrencias realidad não é complemento de volver. Há duas exceções, um uso de volver como causativo e outro como verbo de cambio, respectivamente:

5) todo a cambio de tus sueños, porque eres la única que ha logrado volverlos realidad.

6) desgarra la superficie del suelo entre las [53] fauces del cataclismo final, que se vuelve horror, realidad, vivencia súbita, algo esponjoso y palpable cerca de uno, (...)

Como esperado, não houve ocorrências do verbo de cambio ponerse combinado com realidad. A busca com poner precedido de pronome e realidad gerou uma ocorrência, em que há a expressão en realidad. Já a busca com poner sem o pronome e realidad gerou 14

\footnotetext{
$4 \quad$ O Dicionário Explicativo Combinatório (DEC) é um modelo de dicionário baseado na TST, que emprega as FLs.

$5 \quad$ Os verbos hacerse, ponerse e volverse são objeto da pesquisa para dissertação de mestrado que serviu de base para este trabalho.
} 
entreCaminos, v.1, jul-dez 2015

ocorrências. Temos a expressão en realidad e construções de poner causativo combinado com outros complementos, como por exemplo:

7) Gabriel, en cambio, no ponía en duda la realidad del coronel Aureliano Buendía

Também chama a atenção o verbo de cambio convertirse. Esse verbo aparece combinado com realidad em 42 ocorrências. Predominam as construções em que convertirse funciona como verbo de cambio (31 ocorrências), mas há 11 ocorrências de convertir causativo. Em ambos os casos o verbo pede a preposição en. São exemplo, respectivamente:

8) En la capital de la República el voto independiente se está convirtiendo en una realidad.

9) venció a Nigeria por 3-1 y convirtió en realidad su sueño de clasificarse para los octavos de final

Dessa forma, pode-se dizer que temos, no que tange aos verbos de cambio e suas contrapartes causativas, as seguintes funções léxicas para descrever as colocações com o substantivo realidad:

$$
\begin{aligned}
& \text { IncepOper }_{1}(\text { realidad })=\text { hacerse }, \text { convertirse }[\text { en } ~] \\
& \text { CausOper }_{1}(\text { realidad })=\text { hacer, convertir }[\text { en } ~]
\end{aligned}
$$

\section{Conclusão}

A pesquisa em corpus permite verificar as combinações presentes na língua para os verbos de cambio, revelando seus padrões de uso. Embora o critério estatístico não seja absoluto para identificar uma colocação, sobretudo porque um corpus, embora reflita o comportamento linguístico, não é capaz de esgotá-lo, acreditamos que pode ser usado de maneira complementar a outros tipos de análise.

No modelo de trabalho aqui exposto a pesquisa em corpus funciona como um ponto de partida para que as colocações sejam identificadas, uma vez que as mesmas podem passar despercebidas mesmo para os falantes da língua, que as empregam rotineiramente. 0 fato de uma colocação não aparecer no corpus, ou aparecer em registro único, não pode fundamentar a afirmação de que tal construção não ocorre na língua, porém é um indício que justifica a exclusão de um possível valor em uma função léxica. 
Ao trabalhar com a noção de sinonímia em um sentido mais amplo, a TST, por meio das funções léxicas, permite uma sistematização capaz de colocar em perspectiva as colocações. A TST tem uma vocação eminentemente prática, o que faz com que acomode a evidência de diferentes pesquisas. Essa proposta se molda à razão de ser do ensino das colocações, que é, em última análise, garantir maior naturalidade à produção do aprendiz de uma língua estrangeira.

Trabalho submetido para publicação em 31 de março de 2014.

Trabalho aceito para publicação, como Anais das Jornadas de Pós-Graduação do Programa de Língua Espanhola e Literaturas Espanhola e Hispano-Americana, em 24 de abril de 2014.

\section{Referências}

ALONSO RAMOS, M. Las Funciones Léxicas en el modelo lexicográfico de I. Mel'čuk. Tese de doutoramento inédita. Departamento de Lengua Española, UNED, Madrid, 1993.

. Las construcciones con verbo de apoyo. Madrid: Visor, 2004.

DAVIES, M. Corpus del español (100 millones de palabras, siglo XIII - siglo XX), 2002.

DEMONTE, V.; MASULLO, P. J. "Los complementos predicativos”. In: BOSQUE, I.; DEMONTE, V. (Dir.) Gramática descriptiva de la lengua española. Madrid : Espasa Calpe, 2000. p. 2461 2523. v. 1.

MEL'ČUK, I. A. "Meaning-Text Models: A Recent Trend in Soviet Linguistics". Annual Review of Anthropology, Vol. 10, p. 27-62, 1981.

. "Lexical Functions: A Tool for the Description of Lexical Relations in a Lexicon". In: WANNER, L. (ed.) Lexical Functions in Lexicography and Natural Language Processing. Amsterdam/ Philadelphia: John Benjamins Publishing Company, 1996. p. 37-102. 
entreCaminos, v.1, jul-dez 2015

- "Collocations and Lexical Functions". In: COWIE, A. P. (Ed.) Phraseology. Theory, Analysis, and Applications. Oxford: Clarendon Press, 1998. p. 23-53.

Semantics and the Lexicon in Modern Linguistics. Artigo não publicado. 2001.

REAL ACADEMIA ESPAÑOLA; ASOCIACIÓN DE ACADEMIAS AMERICANAS. Nueva gramática de la lengua española. Madrid: Espasa Calpe, 2009.

SINCLAIR, J. Corpus, Concordance, Collocation. Oxford: Oxford University Press, 1991. 